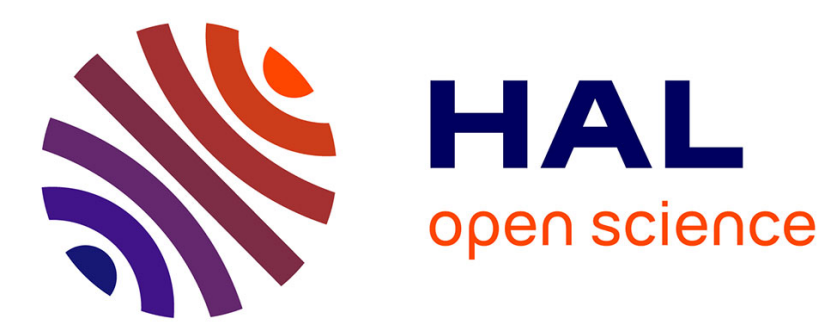

\title{
Observation of optical emission from beam-foil excited Li-
}

\author{
A. Denis, J. Desesquelles
}

\section{To cite this version:}

A. Denis, J. Desesquelles. Observation of optical emission from beam-foil excited Li-. Journal de Physique Lettres, 1981, 42 (3), pp.59-61. 10.1051/jphyslet:0198100420305900 . jpa-00231873

\section{HAL Id: jpa-00231873 https://hal.science/jpa-00231873}

Submitted on 1 Jan 1981

HAL is a multi-disciplinary open access archive for the deposit and dissemination of scientific research documents, whether they are published or not. The documents may come from teaching and research institutions in France or abroad, or from public or private research centers.
L'archive ouverte pluridisciplinaire HAL, est destinée au dépôt et à la diffusion de documents scientifiques de niveau recherche, publiés ou non, émanant des établissements d'enseignement et de recherche français ou étrangers, des laboratoires publics ou privés. 


\title{
Observation of optical emission from beam-foil excited $\mathbf{L i}^{-}$
}

\author{
A. Denis and J. Desesquelles \\ Laboratoire de Spectrométrie Ionique et Moléculaire $\left({ }^{*}\right)$, Université de Lyon I, 69622 Villeurbanne Cedex, France
}

(Reçu le 21 octobre 1980, révisé le 8 décembre, accepté le 16 décembre 1980)

Résumé. - Nous avons vérifié par une méthode d'identification des charges par effet Doppler que la raie observée à $348,9 \mathrm{~nm}$ dans un faisceau de lithium excité par feuille de carbone est due à l'ion $\mathrm{Li}^{-}$, en accord avec les prédictions théoriques de Bunge [5].

Abstract. - We have verified by a method of charge assignment by Doppler effect that the line observed at $348.9 \mathrm{~nm}$ in a lithium beam excited by a carbon foil is due to $\mathrm{Li}^{-}$negative ion, in agreement with a calculation of Bunge [5].

Short lifetime levels of negative ions can arise from the capture of electrons in collision with neutral atoms, from the excitation of fast negative ions or by a twostep charge exchange process in fast positive ions. These negative ion states overlap the adjacent continuum of the neutral atom and their nature is strongly influenced by interaction of configurations. For the multiply excited levels deexcitation may occur either via auto-ionization or radiative decay.

Negative helium states have been seen in electron transmission type experiments [1] with single-electron emission into excited states and two-electron emission into the $\mathrm{He}^{+}$ground state as decay modes, or in trapped electron methods. But there are no measurements of negative ion resonance in lithium although they have been predicted [2]. In connection with a tunable laser photodetachment measurement from alkali negative ions by a JILA group [3], Norcross [4] calculated alkali negative ion bound states with configuration $n \mathrm{p}^{2}{ }^{3} \mathrm{P}$ lying just below the first excited state of the neutral atom for every species except $\mathrm{Li}^{-}$.

However, recently Bunge [5] reported on the existence of bound states of core excited negative lithium and the electric dipole transition between them, suggesting the possible occurrence of this radiation in the beam-foil source from a long lived $1 \mathrm{~s} 2 \mathrm{p}^{3}{ }^{5} \mathrm{~S}^{0}$ level of $\mathrm{Li}^{-}$.

It was known that fast $\mathrm{Li}^{-}$is produced by beam gas and beam-foil collision but till Bunge's paper it had been never suggested that a negative ion could emit photons. However a low intensity emission had been observed for some time at different energies (from $50 \mathrm{keV}$ to $450 \mathrm{keV}$ in our laboratory) at $\lambda=348.9 \mathrm{~nm}$,

$\left({ }^{*}\right)$ Laboratoire associé au C.N.R.S. near the wavelength calculated by Bunge for the E1 decay of $\mathrm{Li}^{-}\left(1 \mathrm{~s} 2 \mathrm{p}^{3}{ }^{5} \mathrm{~S}^{0}\right)$ into $\mathrm{Li}^{-}$(1s $\left.2 \mathrm{~s} 2 \mathrm{p}^{2}{ }^{5} \mathrm{P}\right)$ (Fig. 1).

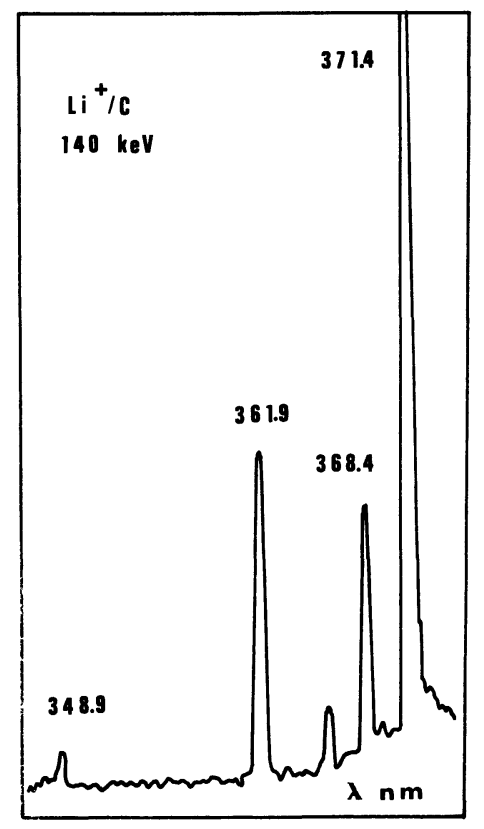

Fig. 1. - Beam-foil spectrum of lithium, $140 \mathrm{keV}$ beam energy, $10 \mathrm{~mm}$ downstream from foil.

We have verified that this beam-foil excited line is really due to $\mathrm{Li}^{-}$ion emission.

From the position of the $1 \mathrm{~s} 2 \mathrm{p}^{3}{ }^{5} \mathrm{~S}^{0} \mathrm{Li}^{-}$level in the global energy diagram of lithium one would expect it to have an excitation function similar to the one for the quartet system of neutral $\mathrm{Li}^{* *}$ [6]. In fact, from spectra recorded from $50 \mathrm{keV}$ to $450 \mathrm{keV}$ it results that the 
projectile velocity dependence of emission is about the same for $\mathrm{Li}^{* *}\left(1 \mathrm{~s} 2 \mathrm{~s} 2 \mathrm{p}^{4} \mathrm{P}^{0}-2 \mathrm{~s} 2 \mathrm{p}^{2}{ }^{4} \mathrm{P}\right) 371.4 \mathrm{~nm}$ and the line observed at $348.9 \mathrm{~nm}$. Thus this line could be emitted by a doubly excited state of neutral Li.

The direct and definitive evidence of $\mathrm{Li}^{-}$optical emission was obtained by means of a Doppler shift experiment (Fig. 2).

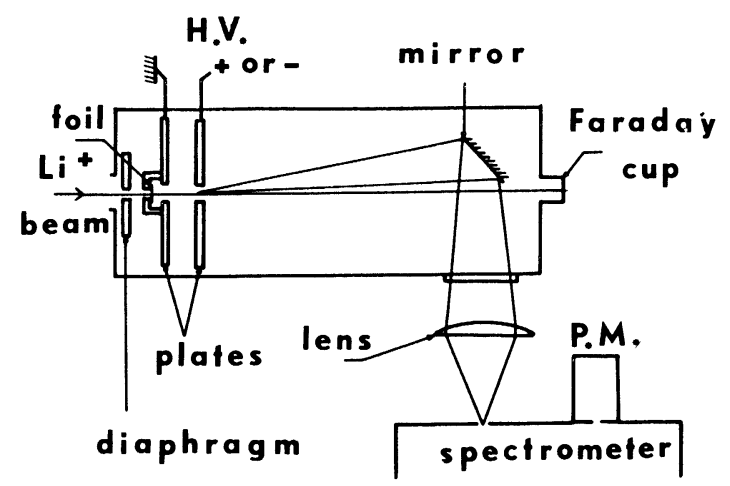

Fig. 2. - Experimental apparatus for separation of charges by Doppler shift.

By accelerating monocharged $\mathrm{Li}^{+}$ions through high voltage $V$ the lithium beam has an energy $E$ (MeV/nucleon) and a velocity

$$
v=\frac{c}{21.2} E^{1 / 2} \text {. }
$$

The light emitted at atomic wavelength $\lambda_{0}$ by fast lithium is observed in the forward direction blue shifted by a quantity

$$
-\frac{\Delta \lambda}{\lambda_{0}}=\beta=\frac{1}{21.2} E^{1 / 2} .
$$

We apply an axial post-accelerating or retarding electric field by means of two parallel plates. The first one supporting the exciting carbon foil is grounded and the second one, $5 \mathrm{~mm}$ downstream, is biased at voltage $\delta V$. The differential Doppler displacement due to the subsequent change in ion velocity will be

$$
\frac{\mp \Delta \lambda}{\lambda}=\frac{1}{42.4} E^{1 / 2} \frac{ \pm \delta V}{V} \text {. }
$$

At $140 \mathrm{keV}\left(E=2 \times 10^{-2} \mathrm{MeV} /\right.$ nucleon for $V=140 \mathrm{kV}$ ) the line at $348.9 \mathrm{~nm}$ will be observed Doppler shifted by $2.3 \mathrm{~nm}$ towards the blue wavelengths. By applying the additional $\pm \delta V=7.5 \mathrm{kV}$, a differential shift of light from monocharged ions will be $\mp 0.062 \mathrm{~nm}$ when observing the light emitted in the forward direction at the exit of the electric field plates.

In our experiment the light is observed at small angle $\theta(\tan \theta \simeq 3 / 21$ and $\cos \theta \simeq 0.985)$ so that the shift is practically equal to the shift calculated at $0^{\circ}$.

An advantage of the forward observation is to minimize the Doppler broadening for a given solid angle as compared to the observation at $90^{\circ}$. The lines are better defined and their shifts are easier to measure. A disadvantage of this device is to destroy the symmetry and to accept the light from a badly defined beam volume.

The lifetime of the upper level $1 \mathrm{~s} 2 \mathrm{p}^{3}{ }^{5} \mathrm{~S}^{0}$ is an important parameter, the order of magnitude of which makes possible or not the experiment. We verified that the experimental lifetime is close to the $2.8 \mathrm{~ns}$ calculated by Bunge. The intensity being divided by about an order of magnitude from the foil to the exit of the high voltage plate, the shape of the line at $348.9 \mathrm{~nm}$ remains measurable at this point of the lithium beam.

The results are shown in figure 3. The apparent wavelength shifts have been determined from the displacement of the centre of gravity of the peaks. The line observed at $371.4 \mathrm{~nm}$ is seen to be insensitive to the post-acceleration or deceleration (Fig. 3a) confirming the assignment to a $\mathrm{Li}^{* *}$ transition. The

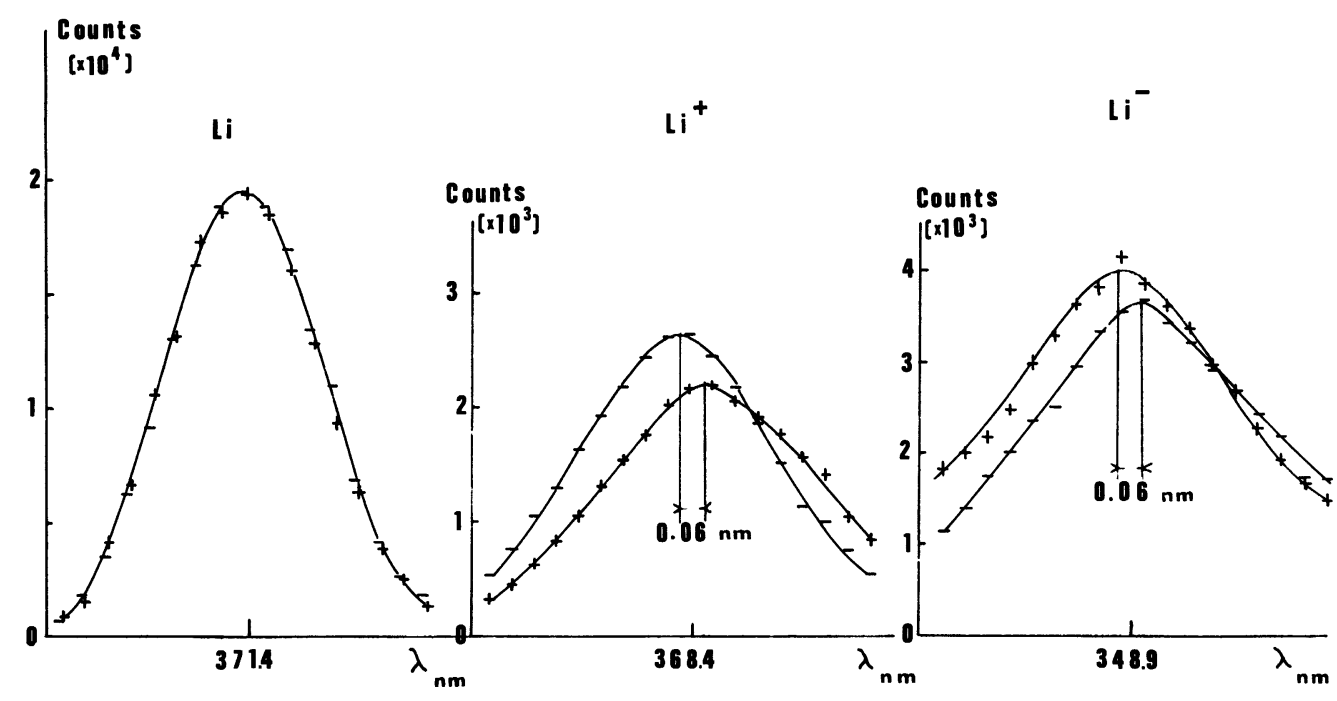

Fig. 3. - Line shifts in accelerating (+) and retarding (-) field. The beam energy is $140 \mathrm{keV}$. The plate voltage is $\pm 7.5 \mathrm{keV}$. For reasons of statistics, the lines at $368.4 \mathrm{~nm}$ and $348.9 \mathrm{~nm}$ were recorded with larger spectrometer slits and time integration is different for every line. 
well known line at $368.4 \mathrm{~nm}$ due to the transition 1s $3 p-1$ s $4 p$ in $\mathrm{Li}^{+}$is shifted towards blue wavelengths when applying a negative voltage which is accelerating for positive ions. The absolute value of this displacement is less than the calculated value due to the partial extension of the observed lithium beam volume between the plates inside the electric field. In the same conditions the previously un-assigned line at $348.9 \mathrm{~nm}$ is shifted by the same quantity, but towards the red part of the spectrum. This is a definitive demonstration of the negative nature of the charge carried by the lithium particle emitting light at $348.9 \mathrm{~nm}$.

During the completion of this work we received a preprint from Berry [7] providing conclusive iden- tification of the charge state of the lithium emission at $348.9 \mathrm{~nm}$, and, since submission of our manuscript we have learned of another independent verification of $\mathrm{Li}^{-}$identification by Mannervik [8]. Both these experiments differ from our work as they rely on the observation of the change of the decay curve in axial electric field related to change in lithium velocity.

Bunge [5] suggests that the two core excited states $\left(1 \mathrm{~s} 2 \mathrm{p}^{3}\right){ }^{5} \mathrm{~S}^{0}$ and $\left(1 \mathrm{~s} 2 \mathrm{p}^{2}\right){ }^{5} \mathrm{P}^{\mathrm{e}}$ are the only bound states of negative lithium. We have begun the analysis by the same Doppler shift method of a number of unidentified lines present in beam-foil spectra [9] to verify this assertion.

\section{References}

[1] e.g. see Williams, J. F., Progress in Atomic spectroscopy, Part B, ed. by W. Hanle and H. Kleinpoppen (Plenum, N.Y.) 1979 , p. 1031.

[2] Schulz, G. J., Rev. Mod. Phys. 45 (1973) 378.

[3] Patterson, T. A., Hotop, H., Kasdan, A., Norcross, D. W. and Lineberger, W. C., Phys. Rev. Lett. 32 (1974) 189.

[4] Norcross, D. W., Phys. Rev. Lett. 32 (1974) 192.

[5] Bunge, C. F., Phys. Rev. Lett. 44 (1980) 1450.

[6] For a review on doubly excited states in lithium e.g. see BERRY, H. G., Phys. Scr. 12 (1975) 5.
[7] Brooks, R. L., Hardis, J. E., Berry, H. G., Curtis, L. J., Cheng, K. T. and Ray, W., Phys. Rev. Lett. 45 (1980) 1318.

[8] Mannervik, S., Astner, G. and Kisielniski, M., J. Phys. B 13 (1980) L-441.

[9] Bromander, J., Hultberg, S., Jelenković, B., Liljeby, L. and Mannervik, S., J. Physique Colloq. 40 (1979) C1-10.

larsson, S., Crossley, R. and Ahlenius, T., J. Physique Colloq. 40 (1979) C1-6. 